\title{
Cancer Genome Anatomy Project
}

National Cancer Institute

\section{Source}

National Cancer Institute. Cancer Genome Anatomy Project. NCI Thesaurus. Code C15923.

The Cancer Genome Anatomy Project (CGAP) is an interdisciplinary prog ram to establish the information and technological tools needed to decipher the molecular anatomy of a cancer cell. The Cancer Genome Anatomy Project (CGAP) will unite the newest technologies, along with those both cost-effective and capable of high-throughput, to identify all the genes responsible for the establishment and growth of cancer. CGAP has two overall goals: 1. Enhance discovery of the acquired and inherited molecular changes in cancer. 2. Evaluate the clinical potential of these discoveries. This requires the creation and dissemination of technologies that can read and interpret the molecular features of cancer. 